\title{
BMJ Open Quality Education and training as key drivers for improving the quality of fluid balance charts: findings from a quality improvement project
}

\author{
Alpha Madu (D) , Harshini Asogan, Ajmal Raoof
}

To cite: Madu A, Asogan $\mathrm{H}$, Raoof A. Education and training as key drivers for improving the quality of fluid balance charts: findings from a quality improvement project. BMJ Open Quality 2021;10:e001137. doi:10.1136/ bmjoq-2020-001137

Received 29 July 2020 Accepted 5 August 2021

Check for updates

(c) Author(s) (or their employer(s)) 2021. Re-use permitted under CC BY-NC. No commercial re-use. See rights and permissions. Published by BMJ.

Medicine, Kettering General Hospital, Kettering, UK

Correspondence to Dr Alpha Madu; alpha.madu@nhs.net

\section{ABSTRACT}

Reviewing fluid balance charts is a simple and effective method of assessing and monitoring the hydration status of patients. Several articles report that these charts are often either inaccurately or incompletely filled thereby limiting their usefulness in clinical practice. We had a similar experience in our practice at Kettering General Hospital and conducted a quality improvement project with a goal to increase the number of charts that were completely and accurately filled by a minimum of $50 \%$ in a 1-month period and to reassess the sustainability of this improvement after 6 months. Data from baseline measurements showed that only $25 \%$ of the charts in the ward had accurate measurements, $20 \%$ had correct daily totals and $14 \%$ had complete records of all intakes and losses. We collected feedback from nursing staff in the ward on what challenges they faced in using these charts and how best to support them. Corroborated by evidence from the literature, we discovered that inadequate training was a major factor responsible for the poor quality of documentation in these charts. Using simultaneous plan-do-study-act cycles, we designed and delivered personalised teaching on fluid balance chart documentation to the nursing staff. Subsequent data showed remarkable improvements in all the parameters we assessed. For instance, the proportion of charts with accurate measurements increased by $55 \%$ and those with complete entries by $122 \%$. Unfortunately, we were unable to demonstrate sustainability of these improvements as our second set of data collection coincided with the SARS-CoV-2 outbreak. In this project, we were able to demonstrate that simple and cost-efficient measures such as adequate training of nursing staff could remarkably improve the quality of fluid balance charts used in our hospitals. We suggest that this training should be included as part of the regular competency assessments for nurses and other healthcare staff.

\section{PROBLEM}

A seemingly simple task to complete, yet highquality fluid balance charts remain an illusion in many medical wards. Anecdotal evidence from the authors' clinical experiences and those of their colleagues, as well as data from the hospital's monthly nutrition and hydration performance index, showed that the quality of documentation in fluid balance charts in our hospital was poor.

Kettering General Hospital is an approximately 540-bed capacity district general hospital providing healthcare services to over 300000 people across north Northamptonshire and south Leicestershire. ${ }^{12}$ There are about 310000 outpatient visits and over 41 000 inpatient admissions annually. The daily emergency department attendance is estimated to be 255 people. ${ }^{3}$

The authors (AM and HA) were new to the hospital and were quick to notice that the quality of documentation in the fluid balance charts used in their ward was below par. During ward rounds, for instance, it was difficult to interpret the previous day's fluid balance records from the charts. We noticed that most of these charts were grossly incomplete and inaccurate. We discovered that almost all the patients on admission in the ward had a fluid balance chart including those for whom fluid balance monitoring was not clinically indicated or requested by the doctors. We also noticed that words such as 'pu', 'pot' and 'wet' were commonly used in the fluid loss/output section of the charts (figure 1). Doctors often abandoned the charts and resorted to visually estimating the patients' fluid intakes and losses, ultimately putting the patients' care at risk, and delaying safe discharges.

This quality improvement project was conducted to improve the quality of fluid balance charts in our ward with a goal to increase the number of charts with accurate and complete documentations by a minimum of $50 \%$ from baseline in a 1-month period and to assess the sustainability of this improvement after 6 months.

\section{BACKGROUND}

Fluid imbalance may represent the cause, component or complication of several disease 

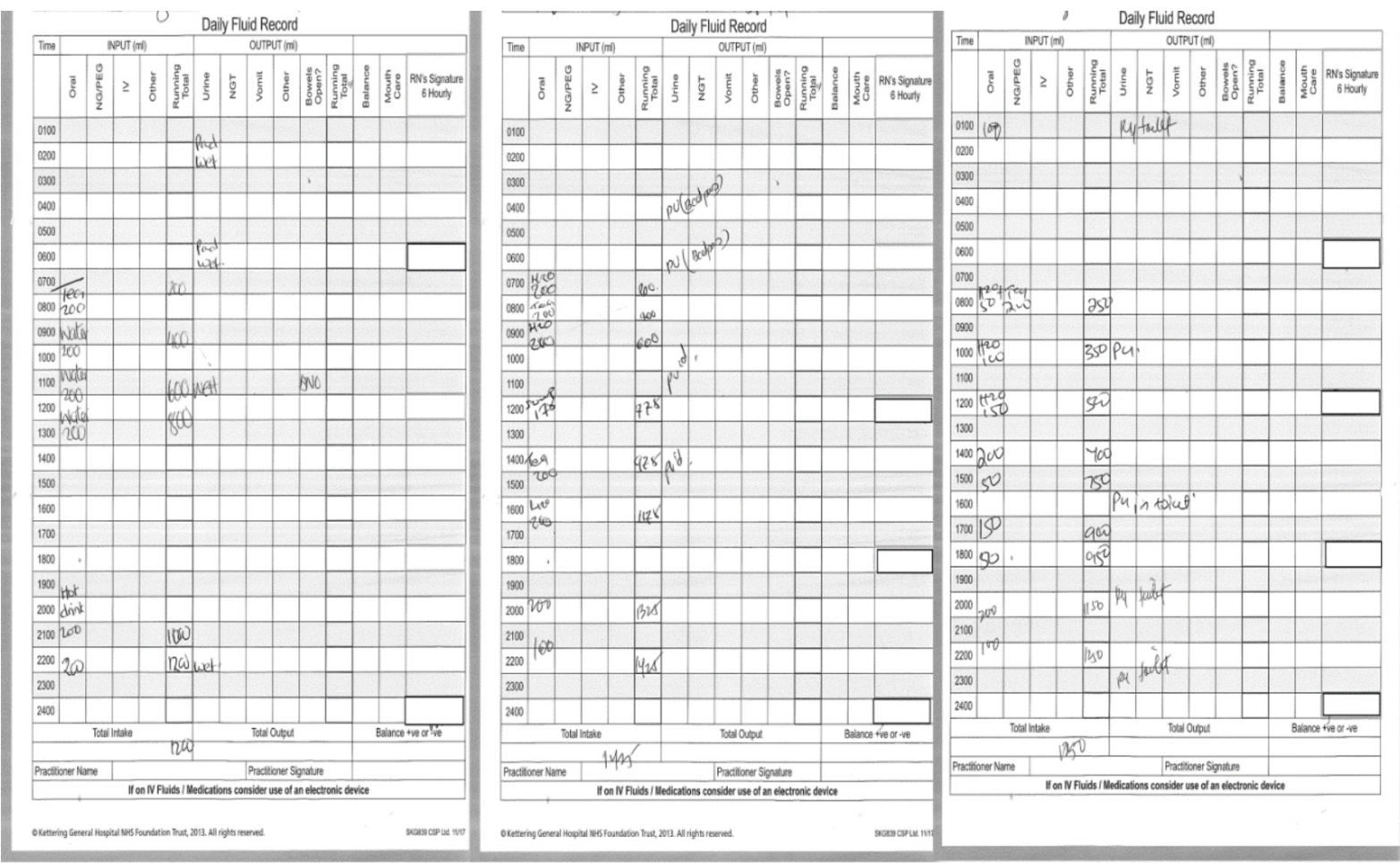

Figure 1 Samples of poorly filled fluid balance charts. (BNO, Bowel not open; 'PU' or 'PU'd' used to indicate that the patient had passed urine).

conditions. In many patients, especially in children and the elderly, restoring the physiological fluid balance status may be the thin line between life and death. Out of the three common methods of monitoring fluid balance in the body-physical examination for signs of dehydration or fluid overload, reviewing fluid balance charts and reviewing blood chemistry results-reviewing fluid balance charts is the simplest, cheapest and most objective method. ${ }^{4}$

However, these charts are notorious for being incomplete or inaccurate with many reports from different clinical practices reporting the same. In a similar project conducted in Milton Keynes Hospital, less than $45 \%$ of the charts surveyed were correctly filled, preintervention. ${ }^{5}$ The study also found that many patients who did not necessarily need fluid balance monitoring were being monitored. In Central Manchester University Hospitals National Health Service (NHS) Foundation Trust, the Fluid Balance Improvement Project found that only $30 \%$ of the charts met their criteria for completion and accuracy. ${ }^{6}$ In Tauton and Somerset Trust, only half of the charts assessed were complete and fluid monitoring was clinically indicated in only $53 \%$ of the patients who had their fluid balance status being monitored. ${ }^{7}$ Reid and her colleagues at East Somerset NHS Trust found that no chart out of the 46 assessed was completed appropriately. They also reported the use of words such as 'toilet', 'wet pad' and 'sips' in filling these charts. ${ }^{8}$ Alani and O'Malley in Ireland, while assessing fluid balance monitoring in patients with heart failure, found that strict monitoring was requested in only 27 out of 40 patients and fluid balance charts were completed in 21 out of these 27 patients. ${ }^{9}$ In an intensive care unit (ICU) in an Egyptian hospital, $65 \%$ of fluid balance charts were accurately recorded. ${ }^{10}$

The most frequently reported factors responsible for poor documentation in fluid balance charts were inadequate training of nurses and other healthcare staff, poor communication among healthcare staff, technical faults with the fluid infusion machines, increased work load and poor time management. ${ }^{810}$ One study reported that less than half of the healthcare staff had received formal training on how to use the fluid balance charts, while another study reported that only $61 \%$ of ICU nurses had adequate knowledge on fluid balance chart documentation. ${ }^{810}$ In these studies, different levels of improvement in fluid balance chart documentation were achieved after education and training of healthcare staff.

\section{Baseline measurement}

This project was conducted in an adult general medical ward (Cranford ward) in Kettering General Hospital. Data for the project were obtained from two sources: patients' clinical notes and feedback from nursing staff.

The fluid balance charts were assessed for quality using two domains: 'accuracy' and 'completeness', rationalising and adapting from methodologies of previous, similar quality improvement projects mentioned earlier in this report. In assessing for accuracy, we checked if all measurements in the chart were accurate, if the entries had been summed up correctly and if the daily totals and balances were correct. In assessing for completeness, we checked 
if fluid monitoring was requested in each patient's clinical notes, if all fluid intakes and losses had been documented, if the times of intake/loss had been recorded and if the entries were legible. A simple proforma was used to record the data which were analysed afterwards on a Microsoft Excel spreadsheet using simple mathematical calculations.

Baseline measurements were collected in August 2019 in a 40-bed general medical ward. In a snap audit on a chosen date, we went through all 40 inpatients' clinical notes. Thirty-five of these notes were found to have fluid balance charts. To ensure uniformity and objectivity, the fluid balance chart from the previous day in each of the 35 notes with fluid balance charts was assessed and the data showed that:

- Measurements were accurate in $25 \%$ of the charts.

- Summations were correct in $17 \%$ of the charts.

- The daily totals and balances were accurate in $20 \%$ of the charts.

- Fluid monitoring was prescribed in $20 \%$ of the charts.

- The entry times were indicated all the time $(100 \%)$.

- Records of all intakes and losses were complete in $14 \%$ of the charts.

- Entries were legible in $74 \%$ of the charts.

Feedback from 11 ward-based nursing staff showed that most of them, $8(72.7 \%)$, had not received any formal training on fluid chart documentation. Most of these staff (7) also reported facing different challenges while using the charts including staff shortage, poor time management as fluid balance monitoring competed for priority with other nursing duties, poor communication among staff and difficulty in monitoring the intakes and losses of ambulatory patients who used the toilets unsupervised. They proffered suggestions which included providing more training for nursing staff, limiting fluid balance monitoring to patients in whom it is clinically indicated and increasing staffing in the ward.

\section{Design}

From the feedback we received and evidence from relevant literature cited earlier, it was obvious that inadequate education and training of health staff was a major factor responsible for the poor quality of fluid balance charts. We discovered that the only training currently available for nursing staff in the hospital was a 30-minute preemployment induction module on documentation where fluid balance monitoring was huddled with other nursing documentation thereby watering down its pertinence. We therefore designed a new teaching module for nurses and healthcare assistants (HCAs) that focused on delivering personalised and specific information on fluid balance chart documentation.

Other interventions we designed were geared towards offering support to alleviate the technical issues the nursing staff faced while monitoring fluid balance. For instance, by ensuring that equipment such as weighing scales and calculators were provided in the ward, we aimed to improve inaccurate measurements and wrong calculations, respectively.

Our team was made up of two junior doctors (authors $\mathrm{AM}$ and HA) and supervised by the ward consultant (AR). We also consulted with the ward matron and sisters-incharge, who helped in disseminating the information to the nursing staff. One major challenge at this stage was fear of adapting to the change or resistance to change. We focused on stakeholder engagement and their buy-in, specifically from the senior nursing staff. Another challenge was difficulty in reaching all the nursing staff in the ward as many of them were either part-time or locum staff. We targeted their hand-over sessions to engage as many of them as we could.

\section{Strategy}

Using simultaneous plan-do-study-act (PDSA) cycles, we implemented our improvement designs. We took two more sets of data after the baseline measurement. The first, taken 4 weeks later, was to assess for immediate improvement in the quality of the charts; and the second,

\section{HOW TO PROPERLY COMPLETE FLUID BALANCE (FLUID MONITORING) CHART}

\section{$>$ Ensure fluid monitoring has been requested by the doctor. Do not routinely start a fluid chart for all patients unless this has been requested. If unsure, ask the Doctor or Nurse-in-charge. \\ $>$ Record clearly, USING ONLY FIGURES, on the fluid balance chart. Do not record entries such as 'wet pad', 'pu'd', 'pu'd-in- toilet' in the chart.}
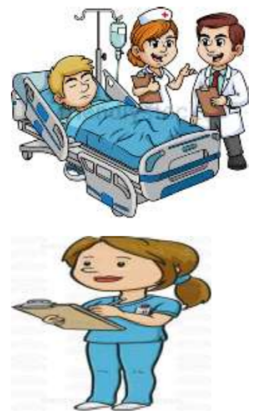

> For patients wearing a pull-up, estimate the quantity of urine in a wet pull-up by weighing it. $1 \mathrm{~g}=1 \mathrm{ml}$

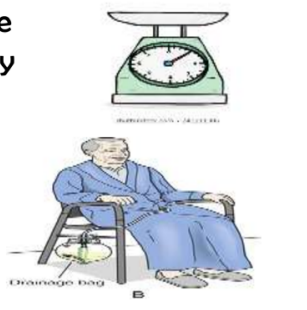

For patient's on catheter, record the quantity of urine whenever the bag is emptied.

> For ambulatory patients, offer them a container to pass urine. Estimate the quantity of urine in the container by weighing it, before discarding.

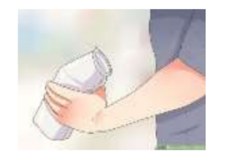

$>$ Estimate quantity of fluid in oral intakes (water, juice, tea, coffee etc) and record it.

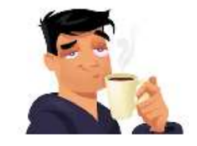

$>$ Add up the inputs and outputs using a calculator. At the end of the day calculate the sum total and the difference between the input and output.

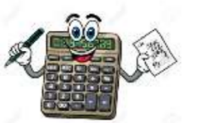

Figure 2 Poster on fluid balance monitoring used as part of our training material. 


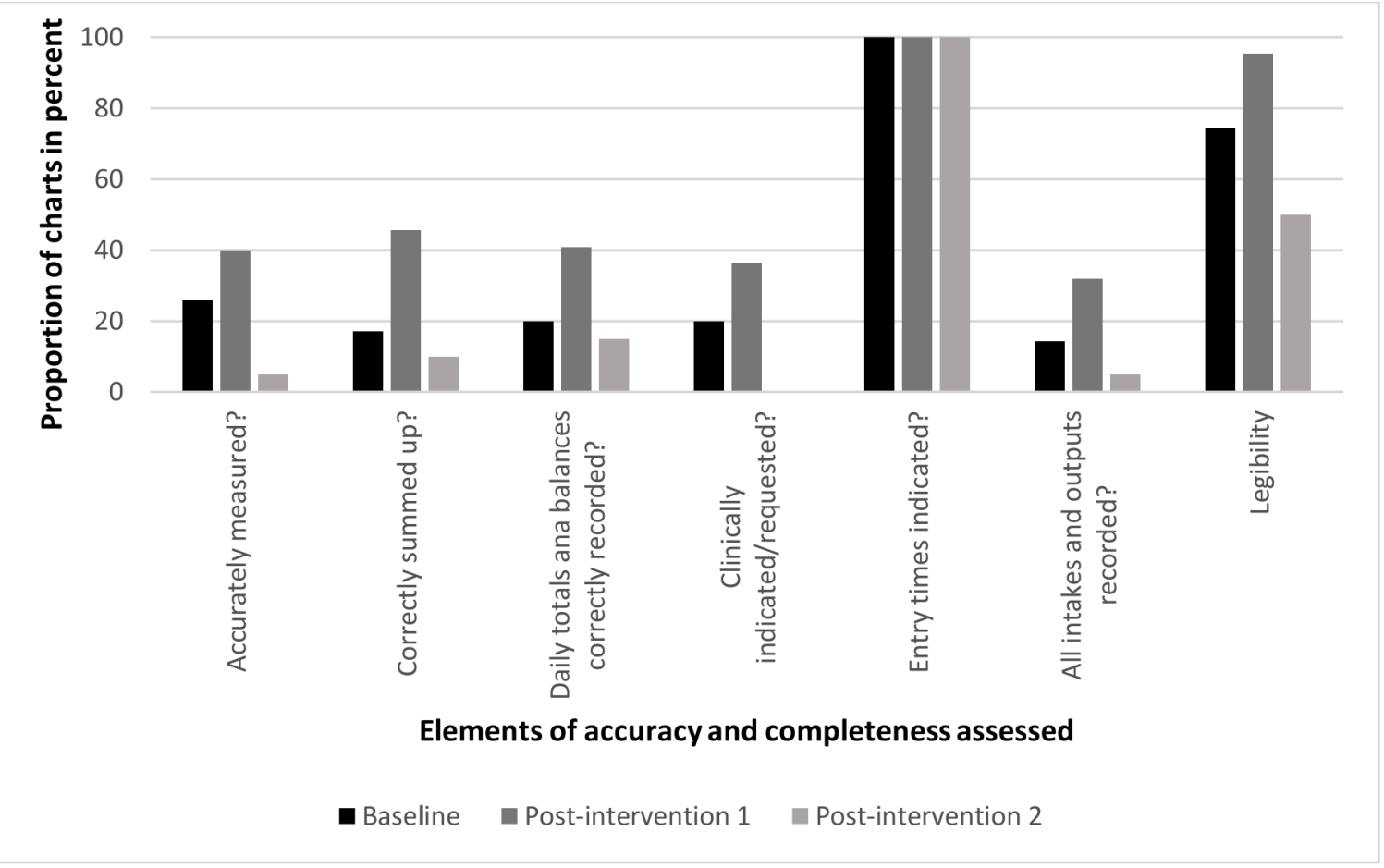

Figure 3 Baseline and post-intervention results expressed as percentages.

taken 6 months later, for sustainability. Our PDSA cycles were as follows:

\section{PDSA cycle 1}

Having identified inadequate training as a major issue, we delivered one-to-one teaching sessions to the nursing staff. We gave short and specific training on the importance of fluid monitoring, on how to take accurate measurements, for example, weighing wet incontinence pads to estimate the volume of urine in them $(1 \mathrm{mg}=1 \mathrm{~mL})$, on how to correctly calculate and record the daily totals and balances, and on the need to make legible entries. We also discouraged the practice of making entries with words such as 'pu' and 'wet'. Lastly, we requested that a chart should only be started for the patients in whom fluid balance monitoring has been explicitly requested by the doctors. We designed picture messages and distributed them as posters and handbills in the ward to serve as a constant reminder (figure 2).

\section{PDSA cycle 2}

We encouraged the ward doctors to specifically indicate which patients needed fluid monitoring, what fluid balance targets were desired and when fluid monitoring should be stopped. We also requested that they call the nurses' attention to improper and unnecessary fluid charts.

\section{PDSA cycle 3}

To obtain more accurate estimations of urine output, we ensured weighing scales were provided in the wards to estimate the volume of urine in wet incontinence pads (1 $\mathrm{mg}=1 \mathrm{~mL})$.

\section{PDSA cycle 4}

We advised that ambulatory patients be asked to record their own intakes and outputs and that, where possible, simple charts should be provided to them to record their intakes and losses themselves, thereby enabling them to become more involved in their own care.

\section{PDSA cycle 5}

We attempted to redesign the fluid balance chart currently in use in the hospital, to create a simpler and more convenient chart. However, our design could not be printed for two logistical reasons: first, we were told that there were thousands of unused charts still on the printer's shelves that needed to be exhausted; and second, there were plans already in place to transition to electronic fluid balance documentation in the hospital.

\section{RESULTS}

Two sets of data were collected after the baseline measurement in August 2019 and the implementation of the interventions. The first set was collected after 4 weeks to assess for improvement, while the second set was collected after 6 months to assess for sustainability of the improvement. Similar to the methodology in our baseline data collection, we assessed all the clinical notes containing fluid balance charts in the ward. In the first post-intervention data, there were 22 notes containing charts out of 40 , and in the second post-intervention data, there were 25. The results are presented in figure 3 .

We recorded remarkable improvement in all the parameters we assessed in our first post-intervention data, 
sometimes even exceeding our projected target of $50 \%$. For instance:

- We achieved a $55 \%$ increase in the number of charts with accurate measurements.

- The number of charts with correctly summed entries (reduction in mathematical errors) and correct daily totals and balances also increased from $17 \%$ to $45 \%$ (a 166\% improvement) and $20 \%$ to $40 \%$ (a $100 \%$ improvement), respectively.

- We recorded a similar trend in 'completeness'; an 82\% increase in appropriateness of fluid balance monitoring and a $122 \%$ increase in complete recording of all intakes and outputs.

- Legibility of entries increased from $74 \%$ to $96 \%$ while entry times remained constant at $100 \%$ because the times are preprinted on the charts.

Unfortunately, in our sustainability assessment (postintervention data 2), we recorded massive drops in all parameters. This data set coincided with the outbreak of the SARS-CoV-2 pandemic. The decline in the quality of documentation was due to strained nursing resources and new infection control protocols because of the pandemic. There was an $87 \%$ drop in the proportion of charts with accurate measurements and correct sums, and a $63 \%$ drop in correctly recorded daily totals. No chart had fluid monitoring requested by a doctor $(0 \%)$. The proportion of charts with legible entries fell by almost a half (47\%), and complete entries fell by $84 \%$.

\section{Lessons and limitations}

We learnt some important lessons from this project. First, we learnt that simple solutions could solve complex problems. Prior to the project, it appeared as if the problem of inadequate fluid balance charts was insurmountable. With simple measures such as training healthcare staff, we were able to demonstrate significant improvement in fluid balance chart documentation.

We also gained more insight into the importance of quality improvement projects in contesting false assumptions. Prior to this project, it was assumed that nurses were adequately trained in fluid balance chart documentation, but our findings did not support this.

Another important lesson we learned was the need to involve multidisciplinary stakeholders early in any quality improvement project. This was something we did not do early enough in our project until we ran into difficulties during the implementation of our strategies. In retrospect, we reflect that as we set out on the task, we found out it was 'bigger' than us. However, we were able to overcome this by quickly involving senior nurses and the ward matron at that stage. By doing this, we allowed the nurses take ownership of the project, and this led to its success. In a future project, we advise that this should be done from the start/planning stage of the project.

The findings of this project have been presented at different meetings of top hospital management staff and have been adopted to be rolled out across the Trust.
A major limitation of the study was the small sample size we used as it was conducted in only one ward. However, we are confident that our findings are generalisable to the rest of the hospital after reactions we received when the project was presented in the hospital.

\section{CONCLUSION}

The problem of poor-quality fluid balance charts and its toll on patients' care is perennial. Carefully designed quality improvement project methodologies are needed to interrogate ways of solving this quagmire.

Similar projects, both locally and internationally, have reported the same bane of poor-quality charts. ${ }^{5-10}$ Education, training and attitudinal change have been shown to be the central theme that drives improvement in the quality of these charts. Our project once again re-emphasised this simple and cost-effective strategy.

This training should be consistent. Although we were not able to objectively demonstrate sustainability (due to the COVID-19 pandemic) in our project, we still advocate that hospitals design succinct modules focusing on fluid balance chart documentation and incorporated into the regular competency assessments for nurses and healthcare assistants and delivered at regular intervals.

The practicability and sustainability of this project are buttressed by the fact that its implementation comes at no added cost. Even as hospitals transition to paperless documentations, education and training remain key to achieving success in improving the quality of fluid balance charts.

Acknowledgements The authors would like to acknowledge the cooperation of the matron, senior nurses and all the nursing staff working on Cranford Ward, at Kettering General Hospital. They would also like to acknowledge the efforts of the deputy medical director and Trust lead on Audits and Quality Improvements, Dr Rabia Imtiaz, for her support in disseminating and rolling out the project across the hospital. Finally, they would like to acknowledge Dr Mohammed Moqsith, consultant stroke physician, for his support and guidance.

Contributors AM designed and led the project, collected data, implemented the strategies, researched the topic and wrote the report. HA participated actively through all stages of the project, and contributed to designing the project, collecting data, implementing the strategies and writing the final report. AR supervised the project, assisted in designing and implementing the strategies, contributed to dissemination of the results of the project and reviewed the project report.

Funding The authors have not declared a specific grant for this research from any funding agency in the public, commercial or not-for-profit sectors.

Competing interests None declared.

Patient and public involvement Patients and/or the public were not involved in the design, or conduct, or reporting, or dissemination plans of this research.

Patient consent for publication Not required.

Ethics approval No ethical approval was required for this project. However, the project was approved by the audit department of Kettering General Hospital.

Provenance and peer review Not commissioned; externally peer reviewed. All data relevant to the study are included in the article.

Open access This is an open access article distributed in accordance with the Creative Commons Attribution Non Commercial (CC BY-NC 4.0) license, which permits others to distribute, remix, adapt, build upon this work non-commercially, and license their derivative works on different terms, provided the original work is properly cited, appropriate credit is given, any changes made indicated, and the use is non-commercial. See: http://creativecommons.org/licenses/by-nc/4.0/. 
ORCID iD

Alpha Madu http://orcid.org/0000-0002-4367-3876

\section{REFERENCES}

1 Care Quality Commission. Kettering general hospital quality report, 2020. Available: https://www.cqc.org.uk/sites/default/files/new_ reports/AAAJ9675.pdf [Accessed 27 Jul 2020].

2 Care Quality Commission. Kettering general hospital NHS foundation trust inspection report, 2019. Available: https://www.cqc.org.uk/sites/ default/files/new_reports/AAAJ0842.pdf [Accessed 27 Jul 2020].

3 Kettering General Hospital. Available: https://www.kgh.nhs.uk/aboutus [Accessed 25 Jun 2020].

4 Shepherd A. Measuring and managing fluid balance. Nurs Times 2011;107:12-16.
5 Jeyapala S, Gerth A, Patel A, et al. Improving fluid balance monitoring on the wards. BMJ Qual Improv Rep 2015;4. doi:10.1136/ bmjquality.u209890.w4102. [Epub ahead of print: 17 Nov 2015].

6 Pinnington S, Ingleby S, Hanumapura P, et al. Assessing and documenting fluid balance. Nurs Stand 2016;31:46-54.

7 Vincent M, Mahendiran T. Improvement of fluid balance monitoring through education and rationalisation. BMJ Qual Improv Rep 2015;4. doi:10.1136/bmjquality.u209885.w4087. [Epub ahead of print: 09 Dec 2015].

8 Reid J, Robb E, Stone D, et al. Improving the monitoring and assessment of fluid balance. Nurs Times 2004;100:36-9.

9 Alani D, O'Malley T. An audit of fluid balance monitoring in patients admitted due to an exacerbation of congestive heart failure. Age Ageing 2018;47:13-60.

10 Asfour HI. Fluid balance monitoring accuracy in intensive care units. IOSR 2016;05:53-62. 